\title{
Toxicity of Single and Mixtures of Antibiotics to Cyanobacteria
}

\author{
EL-Nahhal Yasser*, Alshanti Adli
}

Department of Environmental and Earth Sciences, Faculty of Science, The Islamic University-Gaza. Palestinian Territory

\begin{abstract}
The present study was designed to investigate the disappearance of cyanobacterial mat from fish breeding lakes and to evaluate the phytotoxic effects of Penicillin, Ciprofloxacin, and Tylosin as single and as mixtures to cyanobacterial mats. Phytotoxic effects were measured as growth inhibition of cyanobacteria using spectrophotometer at $680 \mathrm{~nm}$ at low concentrations of antibiotics. Results showed potential phytotoxicity of the tested antibiotics with $\mathrm{EC}_{50}$ values of Penicillin, Ciprofloxacin and Tylosin of $0.13,0.71,5.28 \mathrm{mg} / \mathrm{l}$ respectively. Relative toxicity indicated that Penicillin and Ciprofloxacin were more toxic to cyanobacterial mats than Diuron (standard toxic material). $\mathrm{EC}_{50}$ values of binary mixtures are $0.077,0.103,0.292 \mathrm{TU}$, for (Penicillin+Tylosin), (Ciprofloxacin+Tylosin) and (Ciprofloxacin+Penicillin) respectively; whereas $\mathrm{EC}_{50}$ of the tertiary mixture is $0.034 \mathrm{TU}$. Statistical analysis of the results indicated significant differences between the toxic effects of compounds and their mixtures to cyanobacterial mats. Observation of toxicity of over time indicated that cyanobacterial mats were able to overcome the toxic effects after approximately $72 \mathrm{~h}$ of exposure time. It can be concluded that antibiotics exert dangerous toxic effects to cyanobacterial mat, an important organism in the eco-system. These results are considered the first of its kind in Palestine.
\end{abstract}

Keywords: Cyanobacteria; Penicillin; Tylosin; Ciprofloxacin; Toxicity

\section{Introduction}

Pharmaceuticals and personal care products including all human and veterinary drugs, are emerging contaminants of concern $[1,2]$. Among these pharmaceuticals and personal care products are antibiotics [3]. About 50 to $90 \%$ of antibiotics and/or their metabolites are eliminated from the body through urine and feces which then enter the environment through sewage treatment plants or organic fertilizers application to agricultural lands [4].

Antibiotics have frequently been detected in wastewater effluents, surface waters, ground waters and sea water [5-8] enhancing the generation of resistant genotypes of bacteria in the environment [9].

Antibiotics are applied to control pathogenic bacteria, but their application creates potential risks to indigenous microorganisms in the eco-system [10]. These non-target microorganisms either provide important ecosystem services, such as nutrient cycling, organic matter mineralization and degradation of pollutants [11], or produce oxygen and carbohydrates [12-13]. Thus, antibiotics may affect both primary producers and decomposers, potentially disrupting ecosystem processes.

Antibiotics may enter the environment via several routes, for instance wastes of pharmaceutical plants, wastes from hospitals, manure from animals, containing antibiotics, is often used as a fertilizer and is spread on fields [14].

Natural antibiotics are rarely completely metabolized in the body [15] whereas synthetically modified antibiotics are less biodegradable, more persistent and hydrophilic [16]. Antibiotics may affect the growth of aquatic organisms including cyanobacterial mats which have important ecological position and essential roles in the nutrient cycling and oxygen production [17].

Cyanobacteria, which are member of free-living micro-organisms of the aquatic ecosystem, can fix atmospheric nitrogen [18] and produce oxygen through photosynthetic activity [19] .They have a long history and are diverse and widespread in marine, freshwater, and terrestrial environments.
Number of studies investigated the toxicity of antibiotics to various organisms. For instance toxicity on: Bacterial growth [11], Daphnia magna [20], soil bacteria [21], and algae [22].

Phytotoxicity of amoxicillin at high concentration $(50 \mathrm{mg} / \mathrm{l})$ has been reported to Synechocystis sp. [23], few studies reported the toxic effect of $\beta$-lactam antibiotics and erythromycin, Ciprofloxacin and sulfamethoxazole on algae or cyanobacteria [24-26], the estimated $\mathrm{EC}_{50}$ value against green algae were $1.54-32.25 \mathrm{mg} / \mathrm{L}$. The effects included the reduction in growth rate and inhibition of Photo system II. Furthermore, few reports [27-28] investigated growth-inhibiting and binary joint effects of 12 antibacterial agents on the freshwater green alga Pseudokirchneriella subcapitata (Korschikov) and found potentially synergistic effects in binary mixtures of the same class. Fish breeders and aquacultures from Gaza Strip claimed the disappearance of blue green algae and aquatic weeds in fish lakes and aquaculture industry after application of antibiotics to protect fish from bacterial diseases. Accordingly, the authors designed this study to: 1) characterize phytotoxicity of Penicillin G, Tylosin tartrate, and Ciprofloxacin hydrochloride, as individuals and as mixtures to cyanobacterial mats as an aquatic model of vegetation; 2) study the toxico-dynamics of certain concentrations on the toxicity to cyanobacteria.

\section{Materials and Methods}

\section{Chemicals}

Ciprofloxacin hydrochloride, Penicillin, and Tylosin were purchased from Birzeit-Palestine Pharmaceutical Company. Diuron

*Corresponding author: EL-Nahhal Yasser, Department of Environmental and Earth Sciences, Faculty of Science, The Islamic University-Gaza, Palestinian Territory, P.O Box 108, Tel: +970599634708; E-mail: y_el_nahhal@hotmail.com

Received January 21, 2015; Accepted February 10, 2015; Published February 14, 2015

Citation: Yasser ELN, Adli A (2015) Toxicity of Single and Mixtures of Antibiotics to Cyanobacteria. J Environ Anal Toxicol 5: 274. doi:10.4172/2161-0525.1000274

Copyright: (c) 2015 Yasser ELN, et al. This is an open-access article distributed under the terms of the Creative Commons Attribution License, which permits unrestricted use, distribution, and reproduction in any medium, provided the original author and source are credited. 
was purchased from Sigma Aldrich, Germany. The chemical structure, generic and IUPAC names are shown in (Figure1).

\section{Collection of cyanobacterial mats}

Six cyanobacterial mat samples were collected from the natural area, western part of Wadi Gaza near the Mediterranean Sea where fish farming and aquaculture industry are distributed. Mats collection started early February up to the end of April 2013 following the procedures described previously [29].

\section{Preparation of growth media}

Growth media was prepared by collection of natural water samples from Wadi-Gaza, the same places where cyanobacterial mats were naturally growing. The samples were transferred to the laboratory at The Islamic University-Gaza and left for few hours to allow suspended matter to precipitate. Then the supernatant was collected and cleaned up using sand filter developed in this study. The sand filter consisted of a plastic tube of $3 \mathrm{~cm}$ diameter and $120 \mathrm{~cm}$ long, filled in the bottom with $10 \mathrm{~g}$ of glass wall followed of fine sea sand in the range of 630$20 \mu \mathrm{m}$ mesh. The sand was washed several times with distilled water until the removal of all salts. This was checked by silver nitrate reaction following the descriptions in a previous report [30]. Then filtered again using microbiological filter paper (MFP), white, grid-marked, cellulose ester, $47 \mathrm{~mm}$ diameter and $0.45 \mu \mathrm{m}$ micro mesh under vacuum. The filtrate was autoclaved and used as growth media after cooling to room temperature. The properties of growth media were measured to be adapted with the cyanobacterial mats solution collected from the Wadi. The EC and $\mathrm{pH}$ were measured during all the experiments and adjusted to the range $3600-5100 \mu \mathrm{s} / \mathrm{cm}, 7.5-8.7$ respectively. The growth media was kept in the refrigerator to be used when it is needed [31].

\section{Preparation of cyanobacterial mats suspension}

The collected cyanobacterial mats were incubated in the laboratory at $20-25^{\circ} \mathrm{C}$ for few hours and shaken carefully using electrical shaker, then the aqueous mixture of cyanobacterial mats was left for half an hour. One hundred $\mathrm{ml}$ of the suspension, which contained living cells, was isolated and considered as main suspension of cyanobacterial mats [32]. The EC and $\mathrm{pH}$ of the suspension were measured and adapted to properties of growth media [33]. An amount of the main suspension of the mat was diluted with $100 \mathrm{ml}$ growth media to obtain low concentration solution of the mat with $\mathrm{EC}$ and $\mathrm{pH}$ resembling that of natural environment. The dilution was gently shaken to insure normal distribution of cells by using plates magnetic stirrer- KMC-130 SH for ten minutes [31]. The cyanobacterial mats were diluted to have the following optical density $0.16 \pm 0.03$.

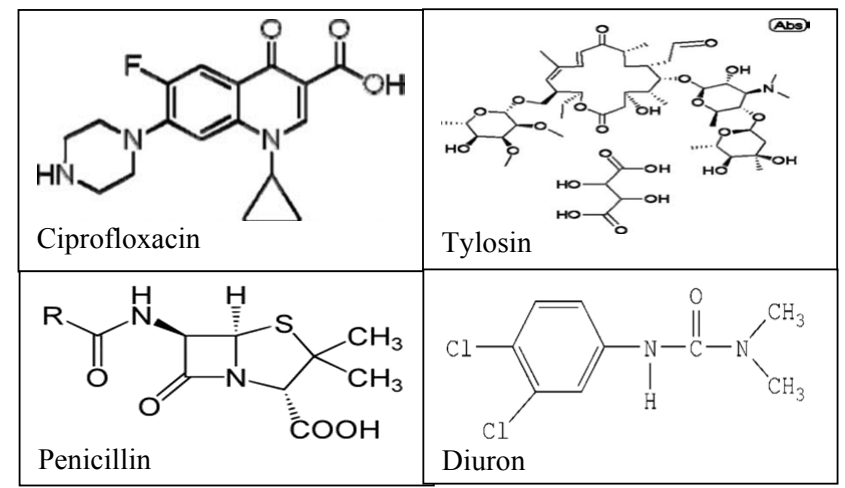

Figure 1: Chemical structure of the tested compounds.

\section{Characterization of cyanobacterial mats growth phases}

The idea behind this experiment is to characterize the log phase of growth so that the toxicity tests can be designed properly. The cyanobacterial mats, having the following optical density $0.16 \pm 0.03$, were allowed to grow under lab conditions, and the optical density was monitored each $4 \mathrm{~h}$ up to $120 \mathrm{~h}$ using CT-220 spectrophotometer at wavelength of $680 \mathrm{~nm}$ [34]. The temperature was maintained at 25 $\pm 1^{\circ} \mathrm{C}$ with $12 \mathrm{~h}$-light: $12 \mathrm{~h}$-dark cycle using 60 watt tungsten lamp. The experiment was performed in three replicates. The population dynamics of cyanobacterial mats was evaluated by plotting OD versus time [35].

\section{Preparation of antibiotics and Diuron stock solutions}

Accurate amounts (4 mg) of Tylosin tartrate, Penicillin G procaine and/or Ciprofloxacin were dissolved separately in 11 volumetric flask using distilled water. The experimental tools and solution were free of chlorine. The following concentrations $0,0.02,0.2,0.4,0.6,0.8$ $\mathrm{mg} / \mathrm{l}$, of the antibiotics were prepared and tested whereas Diuron concentrations were in the following range $0,0.4,4,8,12,16 \mathrm{mg} / \mathrm{l}$.

Binary mixtures of Penicillin G procaine, Tylosin tartrate, and Ciprofloxacin were prepared by mixing together two antibiotics with the ratio of $1: 1(\mathrm{v} / \mathrm{v})$ whereas tertiary mixtures (Mixture T1) of Penicillin, Tylosin, and Ciprofloxacin were prepared by mixing 0.333 : 0.333: 0.333 of each compound together according to the procedure described by Kerkez [32].

\section{Phytotoxicity tests}

The following concentrations $0,0.2,1,2,3$, and $4 \mathrm{mg} / \mathrm{l}$ of the antibiotics and $0,0.4,4,8,12,16 \mathrm{mg} / \mathrm{l}$ diuron were prepared and added to round bottom flasks containing $1 \mathrm{ml}$ of cyanobacterial mat and growth media of total volume of $50 \mathrm{ml}$. The cyanobacterial mats were diluted to match $0.16 \pm 0.03$, total optical density of the suspension [36]. The flasks were kept in the laboratory conditions at $25 \pm 1^{\circ} \mathrm{C}$ and $12 \mathrm{~h}$ light/dark cycle to match the natural conditions. The optical densities of the flasks were recorded at $0,24,48,72,96 \mathrm{~h}$. The recorded data at 24 $\mathrm{h}$ were used to estimate the acute toxicity whereas, the recorded data at $72 \mathrm{~h}$ was used to estimate the chronic effect. The toxicity was estimated by calculating the growth inhibition. High growth inhibition indicates high toxicity and low growth inhibition indicates low toxicity.

The dynamics of Cyanobacterial mats growth (relative growth) in the control samples evaluated by plotting time versus the $\mathrm{OD}_{\max }$ ' $\mathrm{OD}_{0}$ ratio, where $\mathrm{OD}_{\text {max }}$ and $\mathrm{OD}_{0}$ are the optical densities at maximum growth and growth at time zero respectively. According to El-Nahhal et al.[35], \% growth inhibition (GI) which represents toxicity was calculated as follows: $\%(\mathrm{GI})=100 \times[(\mathrm{ODc}-\mathrm{ODt}) / \mathrm{ODc}](1)$, where ODc and ODt are the optical density of the control and the treated samples, respectively.

Regressing GI versus log antibiotic concentrations, enabled the estimation of $\mathrm{EC}_{50}$ values, where $\mathrm{EC}_{50}$ is the effective concentration that caused $50 \%$ growth inhibition compared with the control in any chosen toxicity endpoint [34].

\section{Toxicity of mixtures}

The mixtures mentioned above (Preparation of antibiotics and Diuron stock solutions) were prepared and used as stock solution to make different dilutions. Following the procedure mentioned above, binary and tertiary toxicities were determined. 
Citation: Yasser ELN, Adli A (2015) Toxicity of Single and Mixtures of Antibiotics to Cyanobacteria. J Environ Anal Toxicol 5: 274. doi:10.4172/21610525.1000274

Page 3 of 8

Toxic units $\left(\mathrm{TU}_{\mathrm{s}}\right)$ in mixtures: According to previous calculation [37], toxic units were calculated as follows:

Toxic units=actual concentration in solution/lethal threshold concentration.

Relative toxicity $=\mathrm{EC}_{50}$ of antibiotics/EC $\mathrm{E}_{50}$ diuron (2)

Mixture toxicity index (MTI): To estimate the synergetic and/ or the antagonistic effects of antibiotics mixtures, we calculated the mixture toxicity index (MTI) (Table 1) proposed by Konemann, [38]. $\mathrm{MTI}=1-(\log \mathrm{M} / \log \mathrm{n})$, where $\mathrm{M}=\sum \mathrm{C} / \mathrm{EC}_{50}$ at $50 \%$ effect in the mixture, and $\mathrm{n}=$ total number of compounds in the mixture.

Based on calculation, MTI value can be a negative (antagonism), zero (no effect) and positive value (synergism).

\section{Statistical analysis}

All experiments were performed in three replicates. Averages and standard deviation of the growth inhibition were calculated and fitted to linear regression analysis. The averages of growth inhibition were compared by Tukeys test and P-values were determined to evaluate the significant differences among treatments. One-way ANOVA test which is used to analyze the differences between group means (three or more) was done by using Excel program.

\section{Results}

\section{Growth of cyanobacteria}

The tested antibiotics are widely used in Gaza strip for human, veterinary medication, and livestock and aquaculture growth promotion. These antibiotics are soluble in water and have a solid state at room temperature. More of the physicochemical properties are shown in Table 1 .

Salinity and $\mathrm{pH}$ values of the growth media of cyanobacterial mats were $4068 \pm 599 \mu \mathrm{s} / \mathrm{cm}$ and $8.04 \pm 0.44$ respectively. However, $\mathrm{pH}$ value of natural growth media ranged between 7.5-8.7 and EC ranged from $3600-5100 \mu \mathrm{s} / \mathrm{cm}$

Population growth of cyanobacterial mats in the laboratory is demonstrated by optical density in Table 2. Furthermore, regressing the growth data (Table 2) versus time enabled the characterization of 4 growth phases (Figure 2).

\section{Toxicity tests}

Single toxicity tests of antibiotics: Toxicity of Penicillin, Tylosin,

\begin{tabular}{|c|c|c|c|c|c|}
$\begin{array}{c}\text { Tested } \\
\text { compound }\end{array}$ & MW & $\begin{array}{c}\text { Solubility } \\
\text { in } \mathbf{H}_{\mathbf{2}} \mathbf{O} \mathbf{~ m g / l}\end{array}$ & $\mathbf{p K a}$ & Log $\mathbf{K}_{\text {ow }}$ & Classification \\
\hline Ciprofloxacin & 331.3 & 1.1 & 5.64 & 2.3 & Fluoroquinolones \\
\hline Penicillin G & 334.4 & 22 & 2.62 & 1.67 & $\beta$-lactams \\
\hline Tylosin & 917.1 & 5000 & 3.41 & 13 & Macrolides \\
\hline Diuron & 233.1 & 36.4 & na & 2.85 & Urea \\
\hline
\end{tabular}

Table 1: Some physico-chemical properties of the tested compounds.

\begin{tabular}{|c|c|}
\hline Time (h) & Average optical density \pm SD \\
\hline 0 & $0.090 \pm 0.002$ \\
\hline 24 & $0.105 \pm 0.007$ \\
\hline 48 & $0.305 \pm 0.022$ \\
\hline 72 & $0.305 \pm 0.006$ \\
\hline 96 & $0.157 \pm 0.083$ \\
\hline
\end{tabular}

Table 2: Growth of cyanobacterial mats under laboratory conditions.
Ciprofloxacin and Diuron are shown in Figure 3. The toxico-dynamics of exposure time are shown in Figure 4 . The presented data showed increased toxicity with increased exposure time to $48 \mathrm{~h}$ or $72 \mathrm{~h}$ in all cases, and then a decreasing trend at $96 \mathrm{~h}$.

Table 3 illustrates the toxicity parameters and indicates that Penicillin is the most toxic one followed by Ciprofloxacin as shown by the value of $\mathrm{EC}_{50}$. The lowest value of $\mathrm{EC}_{50}$ indicates the highest toxicity. Statistical analysis showed significant difference between the toxicity of diuron and the toxicity of Penicillin, Ciprofloxacin and/or Tylosin; p-value ranged from $0.023-0.0003$. Toxicity of Tylosin and Penicillin was also significant p-value equals 0.009 .

Toxico-dynamic effect of time: Toxico dynamic effect of Penicillin, Tylosin, Ciprofloxacin and Diuron are shown in Figure 4. It is obvious

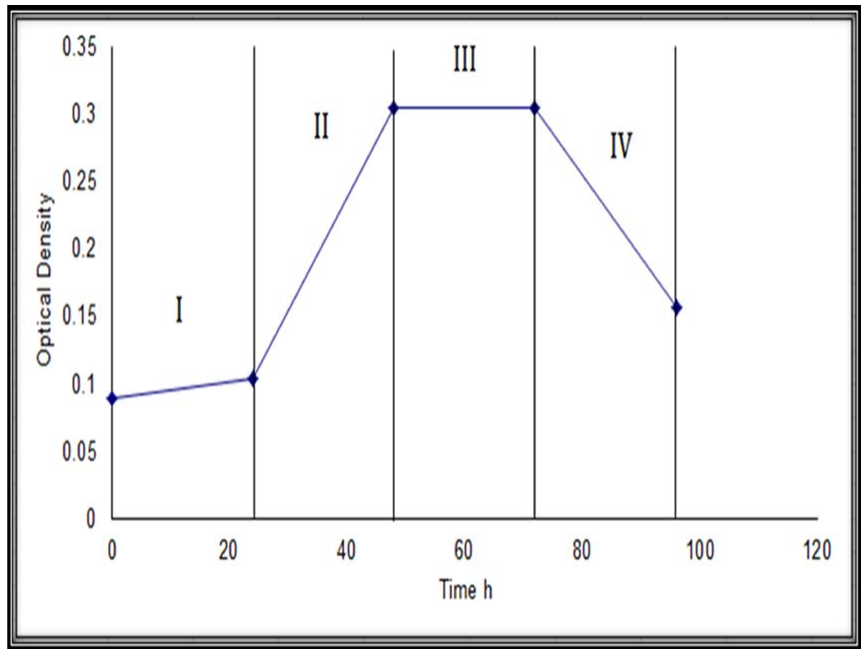

Figure 2: Population growth dynamics of cyanobacterial mats.

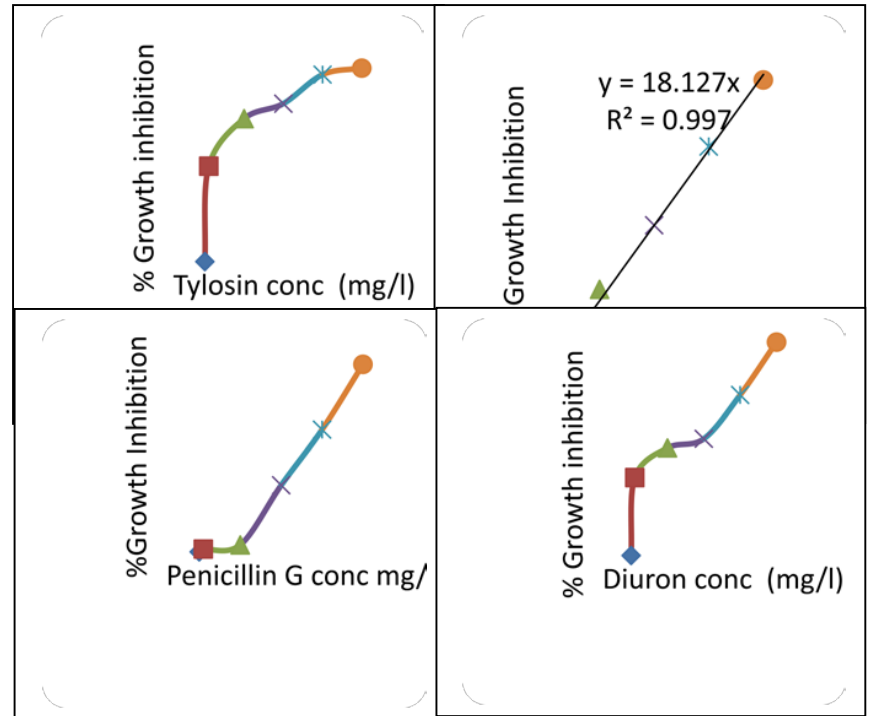

Figure 3: Acute toxicity profiles of Penicillin, Tylosin, Cipro and Diuron to cyanobacterial mats under laboratory conditions. Toxicity measured as growth inhibition of cyanobacterial mat due to the concentration gradients of each antibiotic and the standar material (Diuron). Effect measured after $24 \mathrm{~h}$ of exposure to each concentration. 
Citation: Yasser ELN, Adli A (2015) Toxicity of Single and Mixtures of Antibiotics to Cyanobacteria. J Environ Anal Toxicol 5: 274. doi:10.4172/21610525.1000274

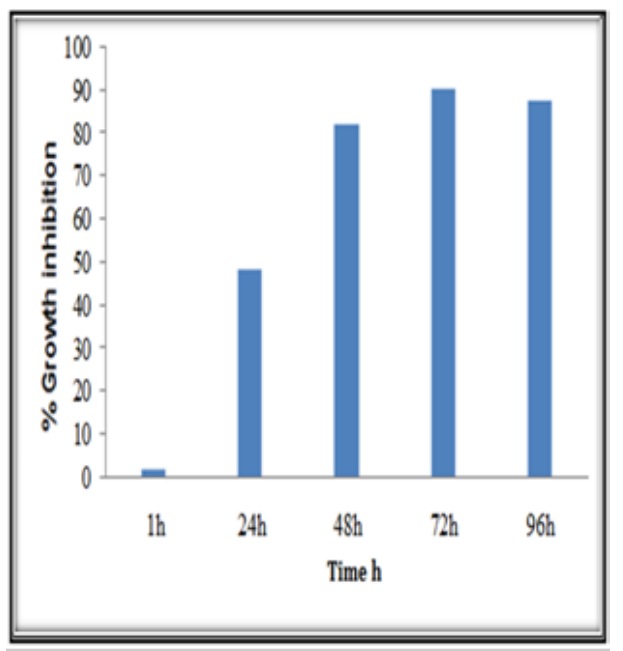

penicillin

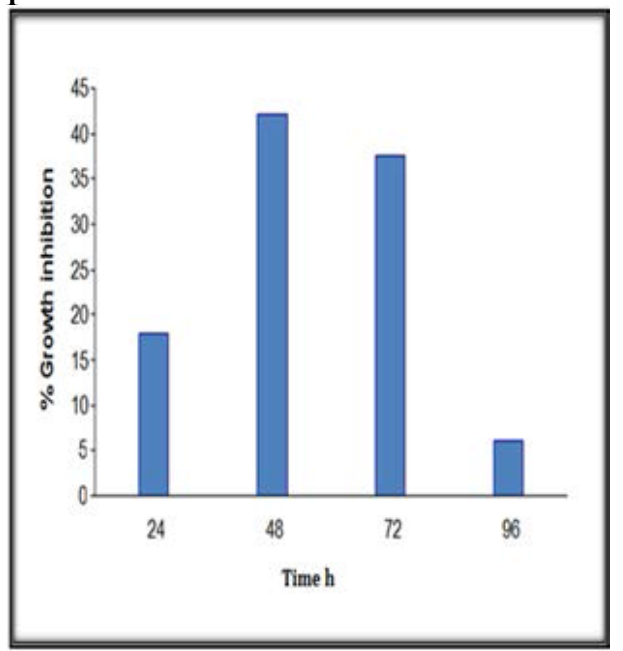

Tylosin

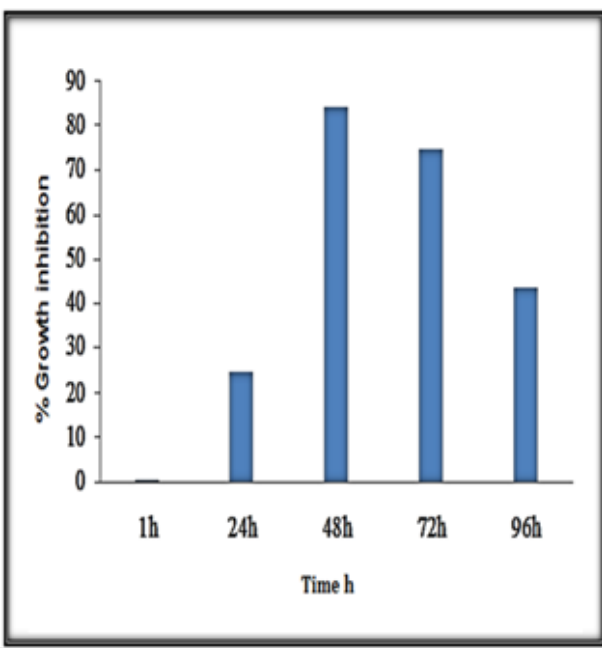

Cipro

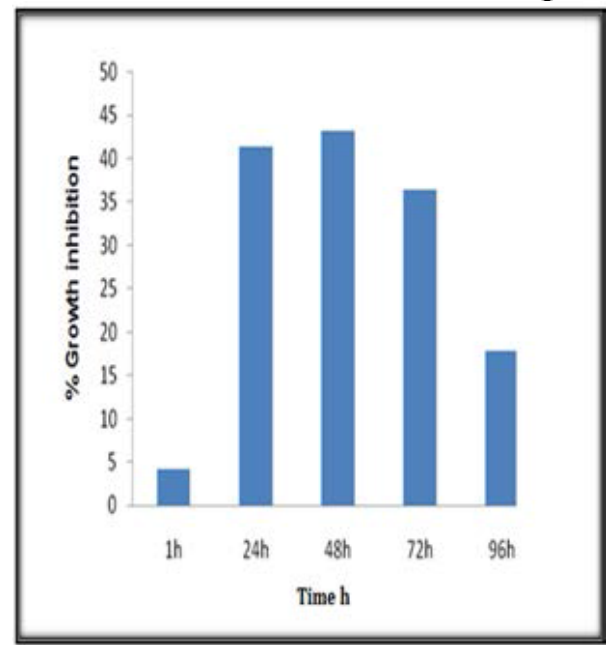

Diuron

Figure 4: Toxico-dynamic effect of penicillin (40 mg/l), Tylosin (20 mg/l), Cipro $(0.2 \mathrm{mg} / \mathrm{l})$ and Diuron $(4 \mathrm{mg} / \mathrm{l})$ on cyanobacterial mats growth after $96 \mathrm{~h}$.

\begin{tabular}{|c|c|c|c|}
\hline Compound & $\mathrm{EC}_{50}$ & $\mathrm{R}^{2}$ & Reg. Eq \\
\hline Diuron & $1.92 \mathrm{mg} / \mathrm{l}$ & 0.82 & $\mathrm{YTI}$ \\
\hline Ciprofloxacin & $0.71 \mathrm{mg} / \mathrm{l}$ & 0.976 & $\mathrm{Y}=0.7269 \mathrm{X}+1.8078$ \\
\hline Tylosin & $5.28 \mathrm{mg} / \mathrm{l}$ & 0.984 & $\mathrm{Y}=0.1906 \mathrm{X}+1.5612$ \\
\hline Penicillin & $0.13 \mathrm{mg} / \mathrm{l}$ & 0.957 & $\mathrm{Y}=0.0994 \mathrm{X}+1.7865$ \\
\hline Penicillin 0.5: Tylosin 0.5=B1 & $0.077 \mathrm{TU}$ & 0.917 & $\mathrm{Nd}$ \\
\hline Cipro 0.5: Tylosin 0.5=B2 & $0.103 \mathrm{TU}$ & 0.966 & $\mathrm{Nd}$ \\
\hline Cipro 0.5: penicillin 0.5=B3 & $0.292 \mathrm{TU}$ & 0.83 & $-3.794 \mathrm{X}+72.217$ \\
\hline $\begin{array}{c}\text { Penicillin 0.33: Tylosin 0.33: } \\
\text { Cipro 0.33=T }\end{array}$ & $0.034 \mathrm{TU}$ & 0.988 & $\mathrm{Y}=43.859 \mathrm{X}+73.46$ \\
\hline
\end{tabular}

Table 3: Toxicity parameters of the tested compounds and Diuron.

that \% growth inhibition of Penicillin increased up to $72 \mathrm{~h}$ and caused about $90 \%$ growth inhibition of cyanobacterial mats. Similar trends were observed for Ciprofloxacin, Tylosin, and Diuron with slight difference in exposure time.

\section{Toxicity of mixtures}

The data presented in Figure 5 clearly demonstrate the toxicity of mixtures to cyanobacterial mats. It is obvious that toxicity of mixtures increased as the concentration of the mixture increased in the solution. Converting the results to the corresponding log scale enabled the calculations of $\mathrm{EC}_{50}, \mathrm{R}^{2}$ values, regression equation and MTI (Table 3). Statistical analysis showed significant differences among all mixture tests; p-values ranged from 0.0001 to 0.0000 . Moreover, no significant difference between $\mathrm{B} 2$ and $\mathrm{B} 3, \mathrm{p}$-value equals to 0.165 , was detected. 


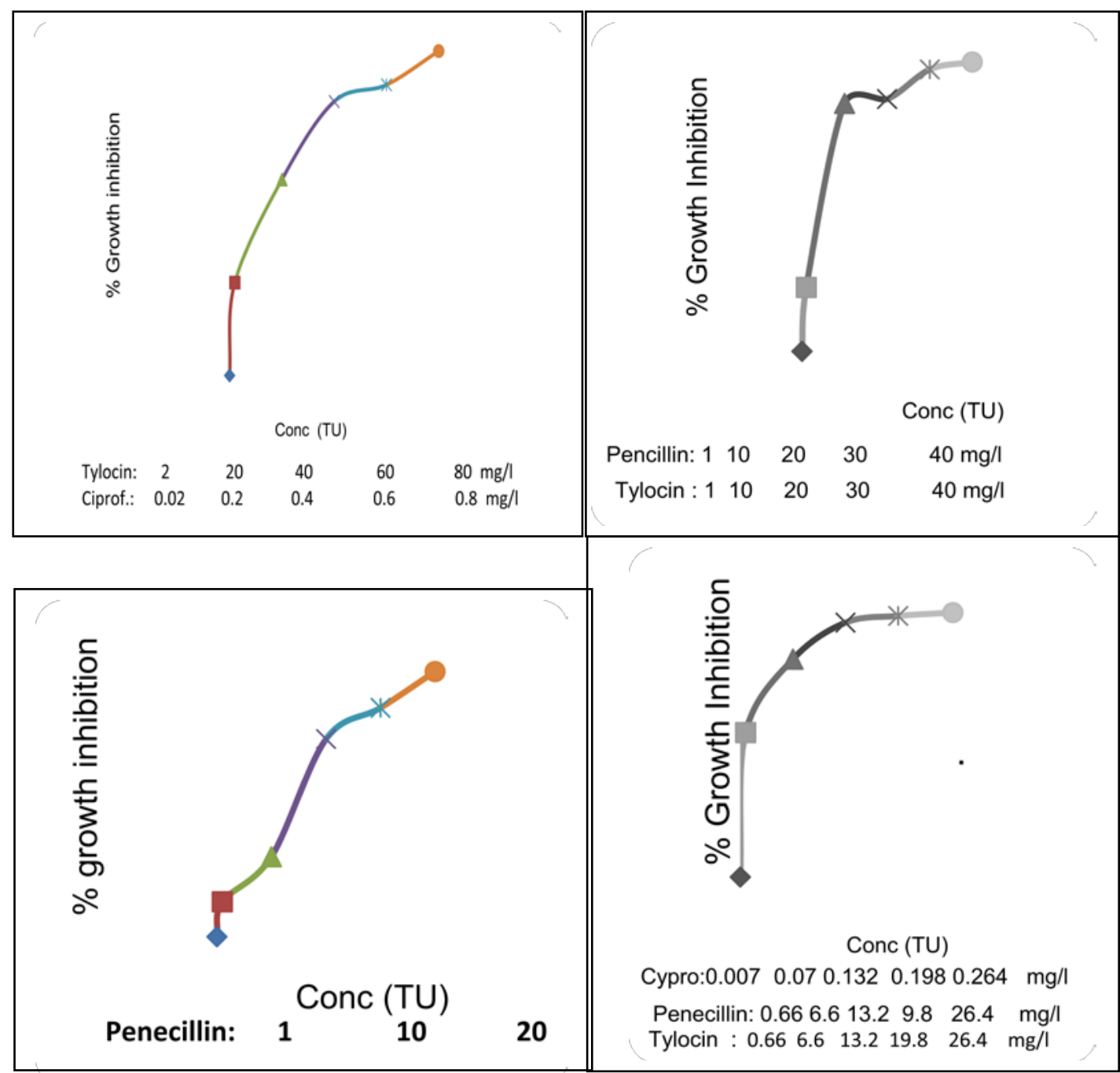

Figure 5: Effect of binary and tertiary mixtures of Penicillin, Cipro and/or Tylosin on cyanobacterial mats growth.

Furthermore, MTI calculations showed negative values. Accordingly, all tests are antagonist effects. However, we can group the MTI values to nearly slightly negative $(-0.792)$ to extremely negative $(-3.7013)$; accordingly, the first one can be categorized to slightly synergistic effect and the one with extreme negative value has the highest antagonistic effect.

\section{Toxico-dynamics of binary and tertiary mixture}

Toxicities of mixtures B1 (50\% Penicillin and 50\% Tylosin), B2 (50\% Tylosin and 50\% Ciprofloxacin) and B3 (50\% Penicillin and 50\% Ciprofloxacin) and T (33.3\% Penicillin, 33.3\% Ciprofloxacin and 33.4\% Tylocin) on cyanobacterial mats are shown in Figure 6.

Effect of time on the toxicity of mixtures: Effect of time on toxicity of different combination ratios of antibiotics mixtures on the growth of cyanobacterial mats is shown in Figure 6. Converting the data to the corresponding log scale enabled the calculation of toxicity parameters. However, the effective concentrations for all mixtures are about 0.025 TU that caused different $\%$ growth inhibition of cyanobacterial mats. Nevertheless, \% growth inhibition reached $40 \%$ in case of Mixture B1, and $25 \%$ in mixture B2 and $15 \%$ in mixture B3. Similar effect was observed in tertiary mixture $\mathrm{T} 1$.
Statistical analysis of toxicity of binary and tertiary mixtures: Statistical analysis of the results indicates significant differences between the effects of mixture $\mathrm{B} 1^{\star} \mathrm{B} 3$ and $\mathrm{B} 1^{\star} \mathrm{B} 2$ whereas $\mathrm{B} 1^{\star} \mathrm{T} 1$ has similar effects regardless of the variations in $\mathrm{TU}$ values. Comparing the effects of binary mixture (B) with the tertiary mixture (T1) indicated significant differences in all cases. To evaluate the synergistic and antagonist effect, we calculated the mixture toxicity indices according to equation of Konemann, [38]. MTI for T1 mixture was less than zero which indicates antagonistic effect (Table 3).

\section{Discussion}

\section{Growth of cyanobacteria}

The data presented in Table 1 clearly indicate the ability of cyanobacterial mats community to grow in different conditions. These values are nearly in accordance with those previously found in Wadi Gaza for other studies [32].

It is obvious (Table 2) that optical density of cyanobacterial mats increased with time indicating normal growth of cyanobacterial mats under laboratory condition. Moreover, calculating the relative growth (Eq. 2) of each experiment (data not shown) and regressing them versus 


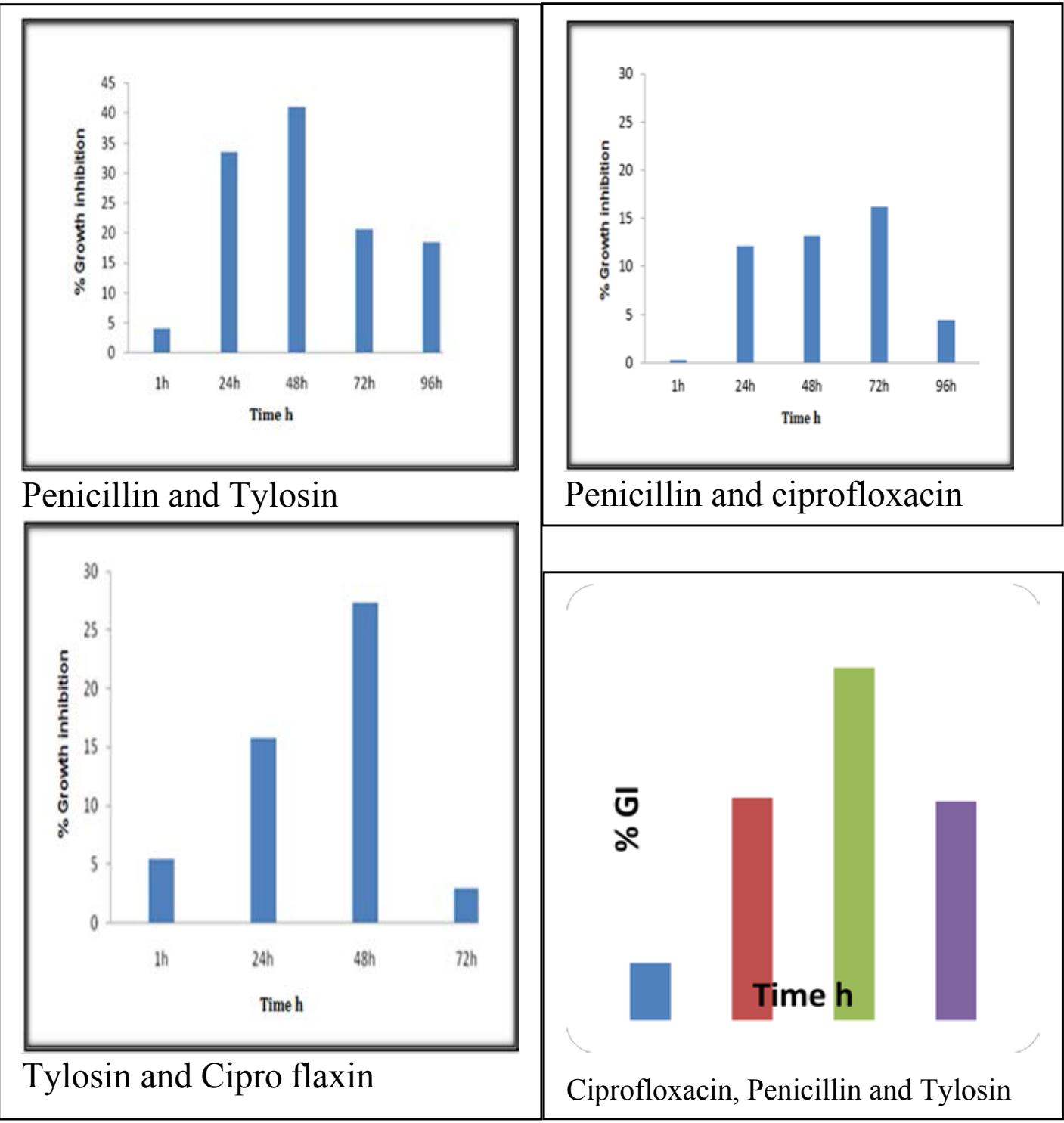

Figure 6: Toxico-dynamics of the binary and tertiary mixtures: B1 (Penicillin+Tylosin), B2 (Tylosin +Ciproflaxin), B3 (Penicillin+Cipro) and T (Penicillin+ciprofloxacin+ Tylosin) mixture on the growth of cyanobacterial mats after $96 \mathrm{~h}$. Exposure time measured at concentration equals to $0.025 \mathrm{TU}$ after $72 \mathrm{~h}$.

time indicated linear relationship with an overlapping of standard deviation at the corresponding points of estimation. This indicates adaptation ability of cyanobacterial mats to grow under laboratory conditions at all experiments. Similar growth features were previously reported [32].

The data in Table 2 demonstrated that lag phase of Cyanobacterial mats lasted $22 \mathrm{~h}$ of lab conditions followed by log phase which reached the maximum growth at $50 \mathrm{~h}$ and stayed at the same level up to 72 $\mathrm{h}$ then followed by the decay phase that reached a minimum growth level after $96 \mathrm{~h}$. An interesting outcome of the study is that the optical density of the cyanobacterial mat at the decay phase is still above the optical density at the starting point. This suggests community changes of the cyanobacterial mats. Our results agree with [39] who found community changes of cyanobacterial mats during growth under laboratory conditions. It is obvious (Figure 2) that 4 growth phases of cyanobacterial mat growth are observed.
The presented data in Figure 2 clearly demonstrated the growth phases of cyanobacterial mats during $96 \mathrm{~h}$. The curve can be divided into four phases I, II, III, and IV. Similar growth phases of cyanobacterial mats growth were reported [34]. These growth phases represented, lag phase, log phase, stationary phase, and decay phase [40]. Moreover, Figure 2 shows that log phase was observed during $50 \mathrm{~h}$. Accordingly, our toxicity investigation focused on this period of bacterial growth.

\section{Toxicity tests}

The presented data in Figure 3 clearly shows steep increases of growth inhibition of cyanobacterial mats as the concentrations of Penicillin and Cyprofloxacin increased in the solution (Single toxicity tests) then no further increase on growth inhibition was observed. In case of Tylosin and Diuron, gradual increases of growth inhibition were observed as their concentrations increased in the solution.

Converting the data in Figure 3 to the corresponding log scale 
enabled the calculation of $\mathrm{EC}_{50}$ of each compound along with the regression coefficient $\left(\mathrm{R}^{2}\right)$ (Table 3 ). It can be seen that Penicillin has the lowest $\mathrm{EC}_{50}(0.13 \mathrm{mg} / \mathrm{l})$ followed by Ciprofloxacin $(0.71 \mathrm{mg} / \mathrm{l})$, then Diuron and Tylocin. The low value of $\mathrm{EC}_{50}$ indicates high toxicity.

The order of $\mathrm{EC}_{50}$ values is $0.13,0.71,1.92$ and $5.28 \mathrm{mg} / \mathrm{l}$, for Penicillin, Ciprofloxacin, Diuron, and Tylosin respectively. Accordingly, Penicillin is the most toxic compound to cyanobacteria, within $72 \mathrm{~h}$. The explanation of these results is that Penicillin refers to the bactericidal action against sensitive organisms during the stage of active multiplication and due to inhibiting bacterial cell wall synthesis [41]. Moreover, the data in Figure 3 revealed that the tested compounds need longer time to reach the target site in cyanobacterial mats, this is in accord with $\mathrm{K}_{\mathrm{ow}}$ of the tested compounds (Table 1). However, decreased toxicity after $48 \mathrm{~h}$ suggests that tolerant species of cyanobacterial mats adapted themselves to the toxic compound and began to grow under the stress of antibiotic concentrations. This can be attributed to community changes that enabled cyanobacteria to survive under chemical stress. Similar results were observed by Abed et al. [39] when they exposed the cyanobacteria mats to diesel oil. Furthermore, the used cyanobacterial mats in this study were many species with different photoautotrophic activities that enabled them to survive under different pollution conditions [39]. Our results agree with previous reports $[32,34]$ that investigated the growth inhibiting effects of eight antibiotics on freshwater cyanobacteria (Microcystis aeruginosa) and green algae (Selenastrum capricornutum), and found that $M$. aeruginosa was two orders of magnitude more sensitive than $S$. capricornutum to the tested antibiotics.

Moreover, our results demonstrated that Ciprofloxacin showed strong toxic effect to cyanobacterial mats with $\mathrm{EC}_{50}(0.71 \mathrm{mg} / \mathrm{l})$. Previous studies reported different $\mathrm{EC}_{50}$ values for Ciprofloxacin (2.97 mg/l-20.6 mg/l) against green algae, cyanobacteria, Lemna sp, Pseudokirchneriella subcapitata and Chlorella vulgaris [34, 42]. These variations in the $\mathrm{EC}_{50}$ values for Ciprofloxacin (Table 3) in the present study and that of previous ones are due to different tested organisms, laboratory conditions, and differences in the tested methods used. In contrast, our results indicated that Tylosin $\left(\mathrm{EC}_{50}=5.28 \mathrm{mg} / \mathrm{l}\right)$, has moderate toxicity and may pose a potential risk to cyanobacterial mats in aquatic systems, whereas previous studies using green algae $P$. subcapitata growth inhibition, reported lower $\mathrm{EC}_{50}$ values 0.95 to 1.38 $\mathrm{mg} / \mathrm{l}$ [34]. The high $\mathrm{EC}_{50}$ value of Tylosin may be due to its instability in acidic and alkaline media [43]. However, Tylosin is a well-known bacteriostatic which inhibits the growth of prokaryotes by binding to the subunit $50 \mathrm{~S}$ ribosome, and thus preventing the translocation of peptides and interfering with protein synthesis.

Another interesting observation is that Penicillin and Ciprofloxacin are more toxic than Diuron (Table 3), the most toxic herbicide to cyanobacterial mats [33]. This suggests that Penicillin and Ciprofloxacin have specific site of action with cyanobacterial mats beside their regular toxic effects to the bacterial growth. The high correlation coefficient value $\left(\mathrm{R}^{2}\right)$ indicates strong positive association between toxicity (\%GI) and concentration. Calculating the relative toxicity (RT) of antibiotics (Eq. 2) indicates that Penicillin and Ciprofloxacin have RT value less than 1; whereas Tylosin has RT value higher than 1 . This indicates that Penicillin and Ciprofloxacin are more toxic than diuron and pose threats to the aquatic eco-system.

\section{Toxicity of mixtures}

The trend of mixture toxicity is similar in all cases, indicating similar response of cyanobacterial mats to the mixture. However converting the data in Figure 4 to $\log$ scale enabled the calculations of $\mathrm{EC}_{50}$ of mixture. The toxicity parameters (Table 3 ) clearly show that mixture B1 (Penicillin and Tylosin) is the most toxic one and has the lowest $\mathrm{EC}_{50}$ value $(0.077 \mathrm{TU})$ among all mixtures. The present study suggests that binary mixtures have antagonistic effect (Table 3). Similar results were reported by Yang et al. [44] for Tylosin-triclocarban, triclosannorfloxacin, and triclocarban-norfloxacin which have slightly antagonistic effect. This may be due to the fact that compounds of a heterogeneous mixture often have different toxic sites and dissimilar modes of action. So concentration addition may not be expected [37]. Another explanation of antagonistic effect could be due to competition for uptake of the same binding sites or suppression of the toxic effect of one drug to the other. In contrast, Chen et al. [27] showed synergistic effect. This is probably due to the fact that we work on cyanobacterial mats which are a community of bacteria.

\section{Toxico-dynamic effects of binary and tertiary mixture on cyanobacterial mats}

It is obvious (Figure 5) that there is a steep increase in growth inhibition as toxic units of the mixture increased in the solution up to 0.2 . Then no further considerable growth inhibition was observed. Table 3 shows the toxicity parameters of mixtures on cyanobacterial mats and indicates the relationship between the compounds of each mixture. According to Konemann, [38], all tested compounds in binary and tertiary mixtures showed antagonistic effect.

Effect of time on the toxicity of different combination ratios of antibiotics mixtures on cyanobacterial mats are shown in Figure 6. Converting the data to the corresponding log scale enabled the calculation of toxicity parameters. However, the effective concentrations for all mixtures are about $0.025 \mathrm{TU}$ that caused different \% growth inhibition of cyanobacterial mats. Nevertheless, \% growth inhibition reached $40 \%$ in case of Mixture B1, and 25\% in mixture B2 and $15 \%$ in mixture B3. Similar effect was observed in tertiary mixture T1.

\section{Conclusion}

The present study provided answers to the claims of fish breeders and aquacultures and indicated the possible disappearance or destruction of cyanobacterial mats as a model of fish lake vegetation. This effect has considerable effects of oxygen production by cyanobacteria. Consequently, it is recommended to use alternatives to these antibiotics in fish lakes as health promoters or protectives. Moreover, the study provides evidence of the toxic effects of Penicillin, Tylosin, and Ciprofloxacin to cyanobacterial mats. Single toxicity tests demonstrated high potential toxicity against cyanobacterial mats. $\mathrm{EC}_{50}$ of individual tests were Penicillin $0.13<$ Ciprofloxacin $0.71<$ Tylosin 5.28 $\mathrm{mg} / \mathrm{l}$. Relative toxicity values indicate Penicillin, and Ciprofloxacin, are more toxic than Diuron to cyanobacterial mats. The interesting outcome of this study is that Penicillin is the most toxic compound to the cyanobacteria mat followed by Ciprofloxacin whereas Tylosin was the least toxic. The effects of time indicated that cyanobacteria mats were able to overcome the toxic effects after $72 \mathrm{~h}$ of exposure time. The mixture $\mathrm{B} 1$ was the most toxic one among all showed antagonistic effect. $\mathrm{EC}_{50}$ of mixtures are: B1 $0.077<\mathrm{B} 20.103<\mathrm{B} 30.292$ and T1 0.034 TU/l. The study also demonstrated the sensitive cyanobacterial mats as aquatic microorganisms to antibiotics. It is recommended that hospital wastes should be treated before transferring to the eco-system.

\section{Acknowledgement}

Dr. Y. El-Nahhal acknowledges Alexander von Humboldt Stiftung Foundation Fellowship Grant no IV-PAL/1104842 STP, Germany. Special thanks go to Prof Dr G.lagaly at Kiel University, Prof Shourrmman Germany. 


\section{References}

1. Daughton CG, Ternes TA (1999) Pharmaceuticals and personal care products in the environment: agents of subtle change? Environ Health Perspect 107 Suppl 6: 907-938.

2. Ungemach FR, Müller-Bahrdt D, Abraham G (2006) Guidelines for prudent use of antimicrobials and their implications on antibiotic usage in veterinary medicine. Int J Med Microbiol 296 Suppl 41: 33-38.

3. Sarmah AK, Meyer MT, Boxall AB (2006) A global perspective on the use sales, exposure pathways, occurrence, fate and effects of veterinary antibiotics (VAs) in the environment. Chemosphere 65: 725-759.

4. Schlüsener MP, Bester K (2006) Persistence of antibiotics such as macrolides, tiamulin and salinomycin in soil. Environ Pollut 143: 565-571.

5. Lindsey ME, Meyer M, Thurman EM (2001) Analysis of trace levels of sulfonamide and tetracycline antibiotics in groundwater and surface water using solid phase extraction and liquid chromatography/mass spectrometry. Anal Chem 73: 4640-4646.

6. Kolpin DW, Furlong ET, Meyer MT, Thurman EM, Zaugg SD, et al. (2002) Pharmaceuticals, hormones, and other organic wastewater contaminants in U.S. streams, 1999-2000: a national reconnaissance. Environ Sci Technol 36 1202-1211.

7. Ye Z, Weinberg HS, Meyer MT (2007) Trace analysis of trimethoprim and sulfonamide, macrolide, quinolone, and tetracycline antibiotics in chlorinated drinking water using liquid chromatography electrospray tandem mass spectrometry. Anal Chem 79: 1135-1144.

8. Lin AY, Tsai YT (2009) Occurrence of pharmaceuticals in Taiwan's surface waters: impact of waste streams from hospitals and pharmaceutical production facilities. Sci Total Environ 407: 3793-3802.

9. Kim S, Aga DS (2007) Potential ecological and human health impacts of antibiotics and antibiotic-resistant bacteria from wastewater treatment plants. J Toxicol Environ Health B 10: 559-573.

10. Flaherty CM, Dodson SI (2005) Effects of pharmaceuticals on Daphnia survival, growth, and reproduction. Chemosphere 61: 200-207.

11. Näslund J, Hedman JE, Agestrand C (2008) Effects of the antibiotic ciprofloxacin on the bacterial community structure and degradation of pyrene in marine sediment. Aquat Toxicol 90: 223-227.

12. Cabello FC (2006) Heavy use of prophylactic antibiotics in aquaculture: a growing problem for human and animal health and for the environment. Environ Microbiol 8: 1137-1144.

13. Maul JD, Schuler LJ, Belden JB, Whiles MR, Lydy MJ (2006) Effects of the antibiotic ciprofloxacin on stream microbial communities and detritivorous macroinvertebrates. Environ Toxicol Chem 25: 1598-1606.

14. Heberer T (2002) Occurrence, fate, and removal of pharmaceutical residues in the aquatic environment: a review of recent research data. Toxicol Lett 131: 5-17.

15. Wise R (2002) Antimicrobial resistance: priorities for action. J Antimicrob Chemother 49: 585-586.

16. Alighardashi A, Pandolfi D, Potier O, Pons MN (2009) Acute sensitivity of activated sludge bacteria to erythromycin. J Hazard Mater 172: 685-692.

17. Breitholtz M, Rudén C, Hansson SO, Bengtsson BE (2006) Ten challenges for improved ecotoxicological testing in environmental risk assessment. Ecotoxicol Environ Saf 63: 324-335

18. An YJ, Kampbell DH (2003) Monitoring chlorophyll- a as a measure of algae in Lake Texoma Marinas. Bull Environ Contam Toxicol 70: 606-611.

19. Herrero A, Flores E (2008) The Cyanobacteria: Molecular Biology, Genomics and Evolution.UK: Caister Academic Press P: 484

20. Wollenberger L, Halling-Sorensen B, Kusk KO (2000) Acute and chronic toxicity of veterinary antibiotics to Daphnia magna. Chemosphere 40: 723-730.

21. Liu F, Ying GG, Tao R, Zhao JL, Yang JF, et al. (2009) Effects of six selected antibiotics on plant growth and soil microbial and enzymatic activities. Environ Pollut 157: 1636-1642.

22. Lützhøft HH, Halling-Sørensen B, Jørgensen SE (1999) Algal toxicity of antibacterial agents applied in Danish fish farming. Arch Environ Contam Toxicol 36: 1-6.
23. Pan X, Deng C, Zhang D, Wang J, Mu G et al. (2008) Toxic effects of amoxicillin on the photosystem II of Synechocystis sp. characterized by a variety of in vivo chlorophyll fluorescence tests. Aquat Toxicol 89: 207-213.

24. BiaÅ,k-BieliÅ, Ska A, Stolte S, Arning J, Uebers U, BÃ schen A, et al. (2011) Ecotoxicity evaluation of selected sulfonamides. Chemosphere 85: 928-933.

25. Liu B, Liu W, Nie X, Guan C, Yang Y, et al. (2011) Growth response and toxic effects of three antibiotics on Selenastrum capricornutum evaluated by photosynthetic rate and chlorophyll biosynthesis. J Environ Sci (China) 23 : 1558-1563.

26. Liu Y, Gao B, Yue Q, Guan Y, Wang Y, et al. (2012) Influences of two antibiotic contaminants on the production, release and toxicity of microcystins. Ecotoxico Environ Saf 77: 79-87.

27. Chen Z, Juneau P, Qiu B (2007) Effects of three pesticides on the growth, photosynthesis and photoinhibition of the edible cyanobacterium Ge-Xian-M (Nostoc). Aquat Toxicol 81: 256-265.

28. González-Pleiter M, Gonzalo S, Rodea-Palomares I, Leganés F, Rosal R, et al. (2013) Toxicity of five antibiotics and their mixtures towards photosynthetic aquatic organisms: implications for environmental risk assessment. Water Res 47: 2050-2064

29. El-Nahhal Y, Awad Y, Safi J (2013) Bioremediation of Acetochlor in Soil and Water Systems by Cyanobacterial mats. Int J Geosc 4: 880-890.

30. El-Nahhal Y, Lagaly G, Rabinovitz O (2005) Organoclay formulations of acetochlor: effect of high salt concentration. J Agric Food Chem 53: 1620-1624.

31. Bonnet JL, Bonnemoy F, Dusser M, Bohatier J (2007) Assessment of the potential toxicity of herbicides and their degradation products to non target cells using two microorganisms, the bacteria Vibrio fischeri and the ciliate Tetrahymena pyriformis. Environ Toxicol 22: 78-91.

32. Kerkez S (2012) Potential Toxicity of the Herbicides; Diuron, Diquat, Terbutryn and their Mixtures to Cyanobacterial mats, Wadi Gaza, Palestine. MSC. Thesis, Department of Environmental science, Faculty of Science, The Islamic University Gaza, Palestine.

33. Sauvant MP, Pepin D, Piccinni E (1999) Tetrahymena pyriformis: a tool for toxicological studies. A review. Chemosphere 38: 1631-1669.

34. Ma J, Zheng R, Xu L, Wang S (2002) Differential sensitivity of two green algae, Scenedesmus obliqnus and Chlorella pyrenoidosa, to 12 pesticides. Ecotoxico Environ Saf 52: 57-61.

35. El-Nahhal Y, Nir S, Polubesova T, Margulies L, Rubin B (1998) Leaching phytotoxicity and weed control of new formulations of alachlor. J Agric Food Chem 46: 3305-3313.

36. Schultz TW, Allison TC (1979) Toxicity and toxic interaction of aniline and pyridine. Bull Environ Contam Toxicol 23: 814-819.

37. Sprague JB, Ramsay B (1965) Lethal levels of mixed copper-zinc solutions for juvenile salmon. J Fish Res Bd Lan 22: 425-432.

38. Könemann $H$ (1981) Fish toxicity tests with mixtures of more than two chemicals: a proposal for a quantitative approach and experimental results. Toxicology 19: 229-238.

39. Abed MA, Safi MN, Köster J, Beer D, El-Nahhal Y, et al. (2002) Microbial Diversity of a Heavily Polluted Microbial Mat and its Community Changes Following Degradation of Petroleum Compounds. Appl Environ Microbol 68: 1674-1683.

40. Zwietering MH, Jongenburger I, Rombouts FM, van 't Riet K (1990) Modeling of the bacterial growth curve. Appl Environ Microbiol 56: 1875-1881.

41. Sweetman S (2009) Martindale: The Complete Drug Reference. Pharmaceutical Press. Thirty-sixth edition, London, P: 213

42. Robinson AA, Belden JB, Lydy MJ (2005) Toxicity of fluoroquinolone antibiotics to aquatic organisms. Environ Toxicol Chem 24: 423-430.

43. Salvatore MJ, Katz SE (1993) Solubility of antibiotics used in animal feeds in selected solvents. J AOAC Int 76: 952-956.

44. Yang LH, Ying GG, Su HC, Stauber JL, Adams MS, et al. (2008) Growthinhibiting effects of 12 antibacterial agents and their mixtures on the freshwater microalga Pseudokirchneriella subcapitata. Environ Toxicol Chem 27: 1201 1208. 